University of Nebraska - Lincoln

DigitalCommons@University of Nebraska - Lincoln

2006

\title{
High Power Density from a Miniature Microbial Fuel Cell Using Shewanella oneidensis DSP10
}

\author{
Bradley R. Ringeisen \\ Naval Research Laboratory, Bradley.ringeisen@nrl.navy.mil \\ Emily Henderson \\ Wright State University \\ Peter K. Wu \\ Southern Oregon University \\ Jeremy Pietron \\ Naval Research Laboratory \\ Ricky Ray \\ Naval Research Laboratory \\ See next page for additional authors
}

Follow this and additional works at: https://digitalcommons.unl.edu/usnavyresearch

Part of the Operations Research, Systems Engineering and Industrial Engineering Commons

Ringeisen, Bradley R.; Henderson, Emily; Wu, Peter K.; Pietron, Jeremy; Ray, Ricky; Little, Brenda J.; Biffinger, Justin C.; and Jones-Meehan, Joanne M., "High Power Density from a Miniature Microbial Fuel Cell Using Shewanella oneidensis DSP10" (2006). U.S. Navy Research. 17.

https://digitalcommons.unl.edu/usnavyresearch/17

This Article is brought to you for free and open access by the U.S. Department of Defense at DigitalCommons@University of Nebraska - Lincoln. It has been accepted for inclusion in U.S. Navy Research by an authorized administrator of DigitalCommons@University of Nebraska - Lincoln. 


\section{Authors}

Bradley R. Ringeisen, Emily Henderson, Peter K. Wu, Jeremy Pietron, Ricky Ray, Brenda J. Little, Justin C. Biffinger, and Joanne M. Jones-Meehan 
High Power Density from a Miniature Microbial Fuel Cell Using
Shewanella oneidensis DSP10

B RADLEY R. RINGEISEN, *,

EMILY HENDERSON, § PETER K. WU, "

JEREMY PIETRON, ${ }^{\dagger}$ RICKY RAY,

B RENDA LITTLE,

JUSTIN C. BIFFINGER, ${ }^{\dagger}$ AND

J O A N N E M. J O NES - MEE H A N $\perp$

Chemistry Division, Naval Research Laboratory,

4555 Overlook Avenue, SW, Washington, D.C. 20375 ,

Oceanography Division, Naval Research Laboratory,

Building 1009, John C. Stennis Space Center,

Mississippi 39529, Materials Science and Engineering

Department, 130 Russ Engineering Center, Wright State

University, Dayton, Ohio 45435, and Department of Physics

and Engineering, Southern Oregon University,

1250 Siskiyou Boulevard, Ashland, Oregon 97520

A miniature microbial fuel cell (mini-MFC) is described that demonstrates high output power per device crosssection $\left(2.0 \mathrm{~cm}^{2}\right)$ and volume $\left(1.2 \mathrm{~cm}^{3}\right)$. Shewanella oneidensis DSP10 in growth medium with lactate and buffered ferricyanide solutions were used as the anolyte and catholyte, respectively. Maximum power densities of 24 and $10 \mathrm{~mW} / \mathrm{m}^{2}$ were measured using the true surface areas of reticulated vitreous carbon (RVC) and graphite felt (GF) electrodes without the addition of exogenous mediators in the anolyte. Current densities at maximum power were measured as 44 and $20 \mathrm{~mA} / \mathrm{m}^{2}$ for RVC and GF, while short circuit current densities reached $32 \mathrm{~mA} / \mathrm{m}^{2}$ for GF anodes and $100 \mathrm{~mA} / \mathrm{m}^{2}$ for RVC. When the power density for GF was calculated using the cross sectional area of the device or the volume of the anode chamber, we found values $\left(3 \mathrm{~W} / \mathrm{m}^{2}, 500 \mathrm{~W} / \mathrm{m}^{3}\right)$ similar to the maxima reported in the literature. The addition of electron mediators resulted in current and power increases of $30-100 \%$.

These power densities were surprisingly high considering a pure $S$. oneidensis culture was used. We found that the short diffusion lengths and high surface-area-to-chamber volume ratio utilized in the mini-MFC enhanced power density when compared to output from similar macroscopic MFCs.

\section{Introduction}

Microbial fuel cells (MFCs) are a promising power source for long-term underwater applications based on their demonstrated ability to generate current by utilizing indigenous

\footnotetext{
* Corresponding author e-mail: bradley.ringeisen@nrl.navy.mil; phone: 202-767-0719; fax: 202-404-8119.

${ }^{\dagger}$ Chemistry Division, Naval Research Laboratory.

$\ddagger$ Oceanography Division, Naval Research Laboratory.

$\S$ Wright State University.

" Southern Oregon University.

${ }^{\perp}$ Current Address: Department of Homeland Security, Science \& Technology Directorate, Office of Research and Development, Washington, DC 20528.
}

nutrients or carbon sources $(1-6)$. In addition, small biofuel cells show promise over batteries or solar cells for applications such as powering autonomous sensors or sensor networks (7-10). Many homeland security, military, and medical applications for miniature sensors make recharging or replacing batteries impossible, while other applications may require power sources to function in environments where there is limited or no sunlight.

Recently, several articles have validated the concept of using energy scavenged from environmental sources to power small sensor nodes $(11,12)$. Due to their simplicity and dependability, batteries are good choices for sensor nodes for short-term applications (1-2 yrs). For nodes that need to function longer, energy harvesting power sources such as photovoltaic cells, piezoelectric conversion of vibration, and biofuel cells will be necessary. Energy scavenging sources can theoretically maintain constant power densities indefinitely $\left(10-300 \mu \mathrm{W} / \mathrm{cm}^{3}\right.$ for vibrations, temperature gradient, and indirect sunlight, to $15000 \mu \mathrm{W} / \mathrm{cm}^{3}$ for direct sunlight), assuming that the scavenged substrate is maintained at constant levels in the environment $(11,12)$. This assumption is particularly flawed for solar power due to dramatic drops in power density, depending upon several uncontrollable environmental conditions.

Recently, the concept of powering autonomous sensors with a miniature biofuel has been discussed. Mano and Heller described a miniature enzyme-based fuel cell for powering small sensors for in vivo biomedical applications $(13,14)$. This application would be classified in the lowest power category for an autonomous sensor system, as the transmitter and receiver were chosen to be within $1 \mathrm{~m}$ of one another. Autonomous sensor networks/nodes would most likely require larger transmission distances and would therefore require powers of $>0.5 \mathrm{~mW}$.

For an MFC to power an autonomous sensor or sensor network, significant reductions in size (current sizes $\sim 0.03-1$ L) must be made (15-21). In addition, relatively high current and power must be maintained to satisfy the projected power needs discussed above $(11,13)$. Few examples exist of miniature MFCs, mainly due to the assumption that the current and power will drop significantly with device size. Reduced size typically results in smaller electrode surface area and cross sectional area of the proton exchange membrane (PEM), which in some cases may limit the total power output (22). For example, Chiao et al. (10) reported a miniature, microfabricated MFC at relatively low power density $\left(5 \mu \mathrm{W} / \mathrm{m}^{2}\right)$ for a $1.5 \mathrm{~cm}^{2}$ cross-section device $\left(0.5 \mathrm{~cm}^{2}\right.$ true surface area) due to low output voltage ( $50 \mu \mathrm{V}$ across 10 ohms). The mini-MFC described herein utilizes closelyspaced electrodes to minimize the proton diffusion distance between anode and cathode chambers. Contrary to a microfabricated design (10), the mini-MFC also incorporates three-dimensional (3D) electrodes that enable large electrode surface areas $\left(36-610 \mathrm{~cm}^{2}\right)$ in a device with a small crosssectional area $\left(2.0 \mathrm{~cm}^{2}\right)$. The chamber volume is also small $\left(1.2 \mathrm{~cm}^{3}\right)$, which creates an MFC with an extremely high electrode surface area-to-chamber volume ratio (30-510 $\mathrm{cm}^{-1}$ ). By increasing the true surface area of the electrodes while maintaining short diffusion lengths in a small device, the mini-MFC design should enhance current and power density per cross-sectional area and chamber volume when compared with comparable macroscopic and microfabricated (2D) MFCs.

VOL. 40, NO. 8, 2006 / ENVIRONMENTAL SCIENCE \& TECHNOLOGY $\mathbf{2 6 2 9}$ 


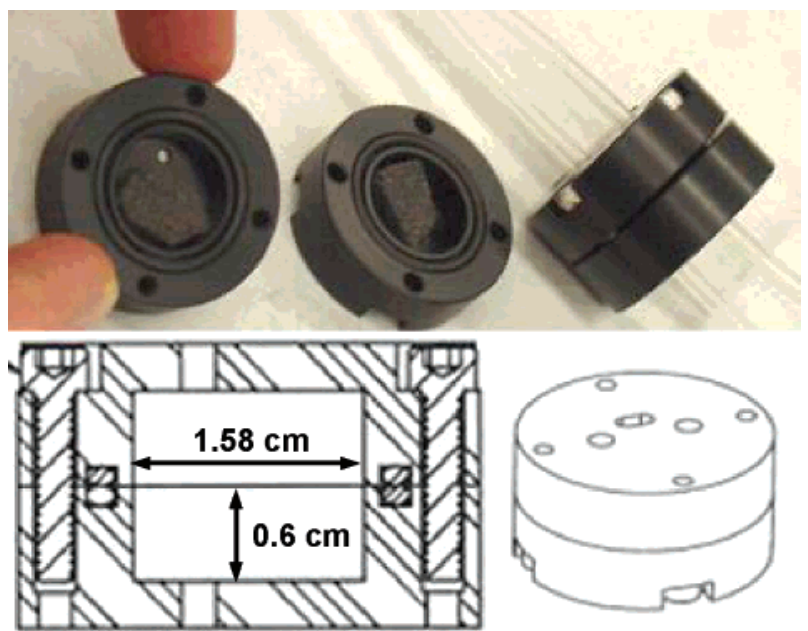

FIGURE 1. Mini-MFC with cross sectional and top views.

\section{Materials and Methods}

Bacterial Culture Conditions. The facultative anaerobe $S$. oneidensis (strain DSP10) was used for all experiments. LuriaBertani (LB) broth (Difco Laboratories, Detroit, MI) was inoculated with DSP10 and incubated aerobically at $25{ }^{\circ} \mathrm{C}$ for 5 days with shaking at $100 \mathrm{rpm}$. Cell counts ranged from 1 to $5 \times 10^{7}$ cells $/ \mathrm{mL}$ as determined by plating. After assembling the mini-MFC (described below), 20-60 mL of DSP10 culture was transferred to a sterile $100 \mathrm{~mL}$ Erlenmeyer flask that was the anolyte reservoir for the mini-MFC experiment. This flask was capped with a sterile rubber stopper, fitted with a cotton-plugged tube open to air and two glass tubes attached to influent and effluent lines. Within 7 min, dissolved oxygen measurements (ISO2 probe, WPI, Inc., Tampa, FL) for both influent and effluent lines showed that the DSP10 culture had scavenged all available dissolved $\mathrm{O}_{2}(0.1 \pm 0.2 \mathrm{ppm})$. Gaseous $\mathrm{O}_{2}$ is most likely present in the headspace above the Erlenmeyer flask, but without stirring or actively forcing oxygen into solution, we find that the solution remains void of measurable dissolved oxygen throughout the experiment. Sodium lactate was used as the substrate, and was added to the flask via pipet every $1-3$ days. Final lactate concentrations were monitored via enzymatic assay. Some bacterial cultures had the soluble electron mediator anthraquinone-2,6-disulfonate (AQDS; 100 $\mu \mathrm{M}$ ) added to the anolyte during fuel cell operation. A single culture was used in the mini-MFC experiment for up to two weeks with little to no drop in performance.

Mini-MFC Assembly and Operation. The catholyte in all experiments was an unstirred $50 \mathrm{mM}$ potassium ferricyanide solution (Sigma-Aldrich, St. Louis, MO) in $100 \mathrm{mM}$ phosphate buffer ( $\mathrm{pH}=7.4$ ), which was continuously open to air. The mini-MFC design with reticulated vitreous carbon (RVC) electrodes and flow tubing is shown in Figure 1. The fuel cell chambers were made from nonconducting plastic. The cross section of the working area of the device was $2.0 \mathrm{~cm}^{2}$ and the anode and cathode chamber volumes were each $1.2 \mathrm{~cm}^{3}$. Two electrodes were formed from either RVC (ERG, Oakland, CA; $60.7 \mathrm{~cm}^{2} / \mathrm{cm}^{3}$ ) or graphite felt (GF) (Electrosynthesis Company, Lancaster, NY; $0.47 \mathrm{~m}^{2} / \mathrm{g}$ ). All experiments used a cathode and anode of equal surface area, with RVC electrodes cut to $0.60 \mathrm{~cm}^{3}$ (true surface area $=37 \mathrm{~cm}^{2}$ ) and GF electrodes cut to $0.13 \mathrm{~g}$ (true surface area $=610 \mathrm{~cm}^{2}$; volume $=1.2 \mathrm{~cm}^{3}=1.2 \mathrm{~mL}$ ). Thin titanium wire was wound around the electrodes to ensure electrical contact. The wire was then fed through a hole in the mini-MFC chambers to connect with external loads. After 3 weeks of exposure to a DSP10 culture, electrodes were examined by environmental scanning electron microscopy (ESEM) to determine if biofilm had developed. After standard preparations, ESEM showed partial biofilm formation on the electrodes.

A $175 \mu \mathrm{m}$ thick proton exchange membrane (PEM) (Nafion 117, Fuel Cell Store, Boulder, CO) was secured between the two chambers during fuel cell operation. Both chambers were sealed by O-rings placed between the Nafion and the outer fuel cell wall. The distance between the electrodes was held constant at $\sim 175 \mu \mathrm{m}$. Two $0.3 \mathrm{~cm}$ o.d. Teflon tubes were attached to both the anode and cathode for influent and effluent flow of anolyte and catholyte, respectively. Flow rates were set between 0.60 and $20 \mathrm{~mL} / \mathrm{min}$ using a peristaltic pump (Masterflex, Cole Parmer, Vernon Hills, IL), with reagents kept at $19^{\circ} \mathrm{C}$ for all experiments. The total volume of fluid residing in the influent and effluent tubing averaged $6 \mathrm{~mL}$, making fluid cycling through both the tubing and chamber ( $7.2 \mathrm{~mL}$ total) no more than $12 \mathrm{~min}(0.6 \mathrm{~mL} / \mathrm{min})$ and no less than $0.4 \mathrm{~min}(20 \mathrm{~mL} / \mathrm{min})$ in total time. Based on these flow rates, the residence time for reagents in the anode and cathode chambers varied from 0.06 to $2 \mathrm{~min}$.

Data Acquisition and Calculations. Potential difference, $V$, between the anode and cathode were measured by a Personal DAQ/54 data acquisition system (IOTech, Cleveland, $\mathrm{OH})$ under one of two configurations: (1) open circuit where $V_{\text {oc }}=$ electromotive force (EMF) of the mini-MFC, or (2) closed circuit configuration, where current, $I$, through a load resistance, $R$, was calculated using Ohm's law: $V=I R$. Output power, $P$, was then calculated by $P=I V$. Voltages were recorded every 2 min by a computer with Personal DaqView software (IOTech, Cleveland, OH). Short circuit currents $\left(I_{\mathrm{sc}}\right)$ were measured with a Fluke 77 multimeter (Fluke, Inc., Everett, WA) when the anode and cathode were connected directly through the multimeter.

The Coulombic efficiency of the mini-MFC was calculated as $E=\left(C_{\mathrm{p}} / C_{\mathrm{T}}\right) \times 100 \%$, where $C_{\mathrm{p}}$ is the total coulombs calculated by integrating the current over the time for lactate consumption (sharp spike in current due to lactate addition), and $C_{\mathrm{T}}$ is the theoretical amount of coulombs that can be produced from the metabolism of lactate, calculated as

$$
C_{\mathrm{T}}=b F\left(\mathrm{~mol}_{\text {lactate }}\right)
$$

where $F$ is Faraday's constant (96485 C/mol-electrons), $b$ represents the number of moles of electrons produced by lactate conversion to acetate $(b=4)$ or $\mathrm{CO}_{2}$ and $\mathrm{H}_{2} \mathrm{O}(b=$ 12), and mol lactate is the added moles of sodium lactate. Since in situ acetate concentrations were not measured, it is possible that part of the loss observed is due to incomplete oxidation of lactate. We use the 4- and 12-electron oxidation as reference points for evaluating the performance of the MFC.

\section{Results and Discussion}

Stable Current and Power Production. Data from the miniMFC were obtained with either GF or RVC electrodes, and each data set was acquired in triplicate with $<10 \%$ variance. Typical function of the mini-MFC with GF electrodes is demonstrated by the data shown in Figure 2a taken at a constant catholyte and anolyte flow rate of $1.5 \mathrm{~mL} / \mathrm{min}$ with a fluid volume of $50 \mathrm{~mL}$ in each reservoir. The solid trace in Figure 2a represents current measured in a closed circuit configuration using a DSP10 culture for the anolyte without exogenous mediators. A $560 \Omega$ load was used for the first 2 days. On day 3 the resistor was switched to a $470 \Omega$ load, increasing the output current, and maximizing power output (break in data shown). Repeated cycles of lactate addition show a rapid current increase $(<30 \mathrm{~min})$ that was sustained initially at $\sim 0.80 \mathrm{~mA}$ and improved to $1.1 \mathrm{~mA}$ after decreasing the load resistor. Lower lactate concentrations produced the same current as higher lactate concentrations $(7.0-55 \mathrm{mM})$, 


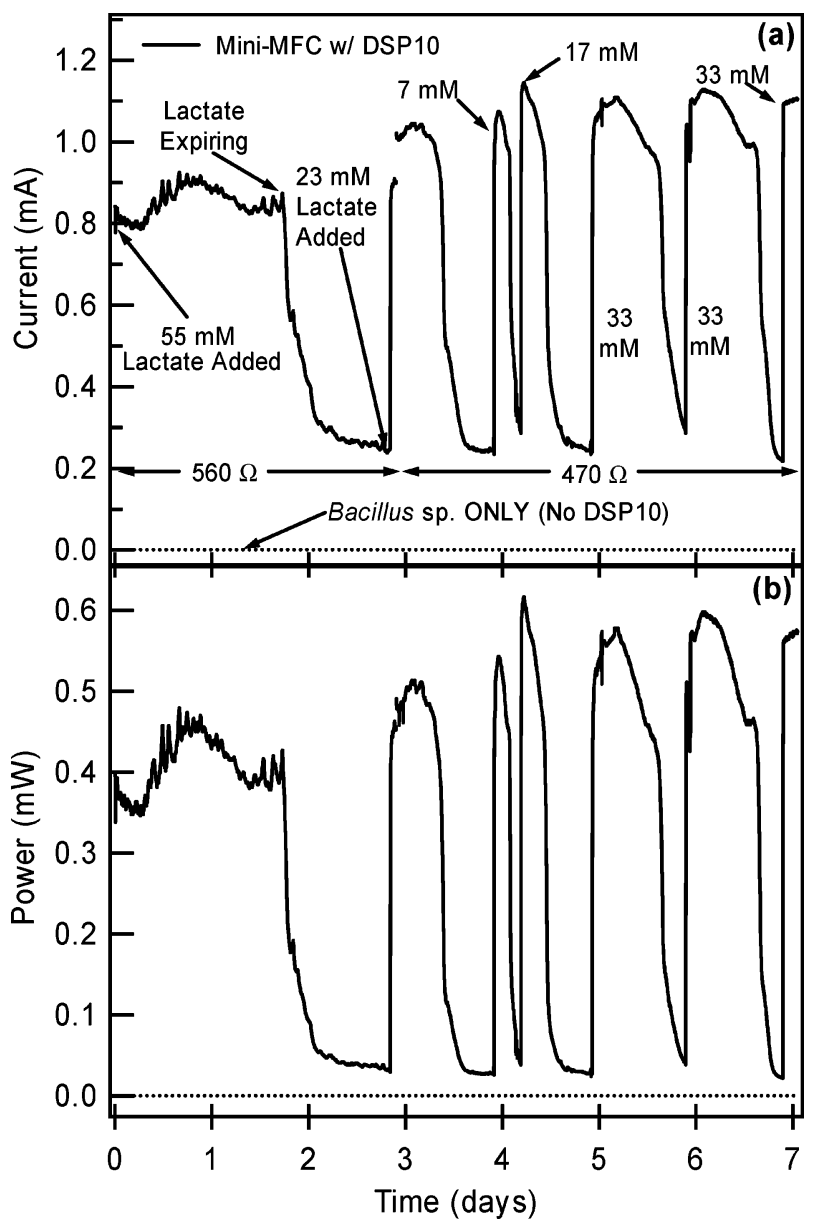

FIGURE 2. (a) Current and (b) power versus run time for the miniMFC for DSP10 (--) and Bacillus sp. (- - -) cultures without exogenous mediators.

although the current was sustained for shorter periods of time at lower concentrations. The corresponding output power for the DSP10 mini-MFC is shown in Figure $2 \mathrm{~b}$. Initial power output fluctuated from 0.37 to $0.45 \mathrm{~mW}$, and successive lactate additions stabilized the performance and increased the output power from 0.55 to $0.6 \mathrm{~mW}$. The control experiment (Figure 2, dashed line) contained no DSP10 cells (LB broth + lactate) and became contaminated on day 2 with Bacillus $s p$. (determined by plating). Throughout the entire control experiment, closed circuit currents were never measured above $5 \mu \mathrm{A}$. Addition of AQDS did not improve the performance of the control experiment (data not shown).

Due to the sharp rise in current after the addition of lactate to the DSP10 culture and minimal current under blank conditions, we conclude that the metabolic activity of DSP10 cells was responsible for the observed current generation by the mini-MFC. In addition, data in Figure $2 \mathrm{a}$ and $\mathrm{b}$ are in contrast to previously reported $S$. putrefaciens MFC data where a $50 \%$ decrease in output power was observed with repeated feedings over 7 days (19). The observed increase in output power from the mini-MFC over time may be due to soluble quinones excreted by Shewanella (self-mediation) or c-type cytochromes localized on nanowires that aid in electron transfer to the anode $(23,24)$.

Mini-MFC Efficiency. Figure 3 is a plot of current versus run time for the addition of 1.4 and $0.75 \mathrm{mmol}$ lactate to GF (solid line) and RVC (dashed line) mini-MFCs, respectively. After lactate addition, the total charge generated from the GF mini-MFC was $C_{\mathrm{p}}=61 \mathrm{C}$. However, there is a background current of $0.20 \mathrm{~mA}$ that occurs both before and after the current spike due to lactate addition. This background is

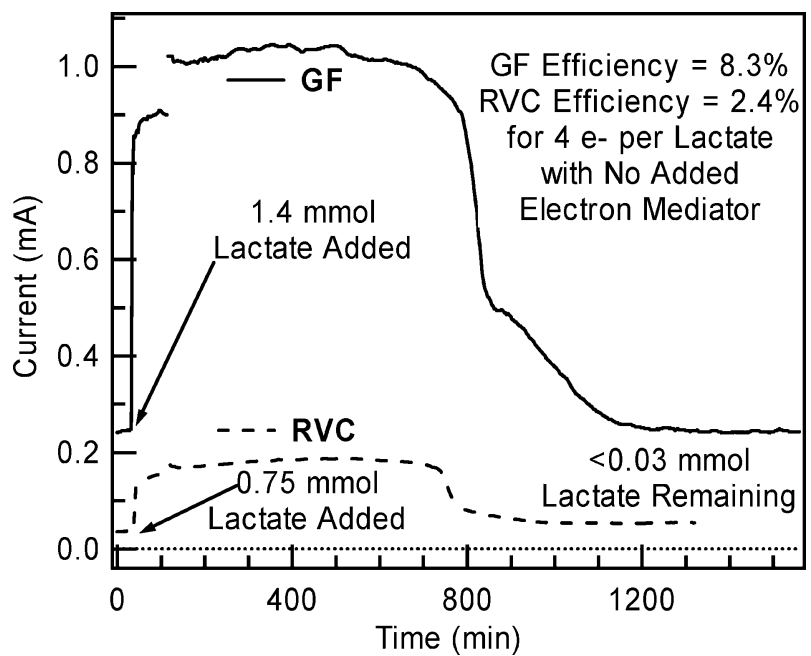

FIGURE 3. Calculated Coulombic efficiency deduced from current at maximum power versus run time for GF (--) and RVC (- - -) for cultures without exogenous mediators.

most likely due to residual nutrients from the LB broth and should be subtracted from the total generated charge, yielding the charge resulting from the lactate addition alone to be $C_{\mathrm{p}}$ (lactate) $=44 \mathrm{C}$. The total available charge from lactate is $C_{\mathrm{T}}$ $=530 \mathrm{C}(b=4)$ and $1600 \mathrm{C}(b=12)$, yielding $E=8.3 \pm 0.5 \%$ and $2.8 \pm 0.2 \%$, respectively (1). Figure 2 shows that the mini-MFC efficiency $(E \sim 8 \%)$ is maintained over the final 5 days of run time, and increases from the first 2 days of operation when $20-30 \%$ lower current was measured. This result implies that the bacterial culture in our mini-MFC remains robust, and that no appreciable fouling of the electrode surface occurs over this time period. RVC electrodes show significantly lower Coulombic efficiencies of $2.4 \pm 0.3 \%$ and $0.8 \pm 0.1 \%$ for $b=4$ and 12 , respectively, with an average current $80 \%$ lower than that for the GF experiments. The increase in efficiency when using GF is most likely due to the increase in current collected at the anode when utilizing a significantly larger surface area electrode.

Voltage and Power Versus Current. Figure 4a is a plot of output voltage versus current for the RVC mini-MFC functioning with and without the addition of an exogenous mediator (AQDS). Standard deviations of voltage measurements were less than $5 \%$ in all cases $(n=4)$. Figure $4 \mathrm{~b}$ is a plot of output power versus current for the RVC mini-MFC, with and without AQDS. We find that the output power and current at maximum power double with the addition of AQDS. These results are indicative of the more efficient electron transfer kinetics when exogenous mediators are added to the anolyte, rather than relying solely on self-mediation or direct electron transfer from the DSP10.

Figure $5 \mathrm{a}$ and $\mathrm{b}$ are plots of output voltage and power versus current for the GF mini-MFC with a $1.5 \mathrm{~mL} / \mathrm{min}$ flow rate. The percent increase in true surface area for GF electrodes versus RVC is $1600 \%$. Following the addition of AQDS, similar results were obtained for the GF electrodes compared to RVC. AQDS dramatically increases $I_{\mathrm{sc}}$ (3.6 from $2 \mathrm{~mA})$, output power (0.8 from $0.6 \mathrm{~mW})$, and current at maximum power $I\left(P_{\max }\right)(2.2$ from $1.2 \mathrm{~mA})$ with GF electrodes. We also found that using higher surface area GF electrodes dramatically improved mini-MFC performance when compared to those constructed with RVC electrodes. Output power, $I\left(P_{\max }\right)$ and $I_{\mathrm{sc}}$ increase by $650 \%, 730 \%$, and $470 \%$, respectively, for the fuel cell operating with no exogenous mediators, and $390 \%, 540 \%$, and $590 \%$ for the mediatorenhanced fuel cell when using GF instead of RVC.

Data shown in Figures 4 and 5 were used to calculate the current density (at maximum power) and power density for 


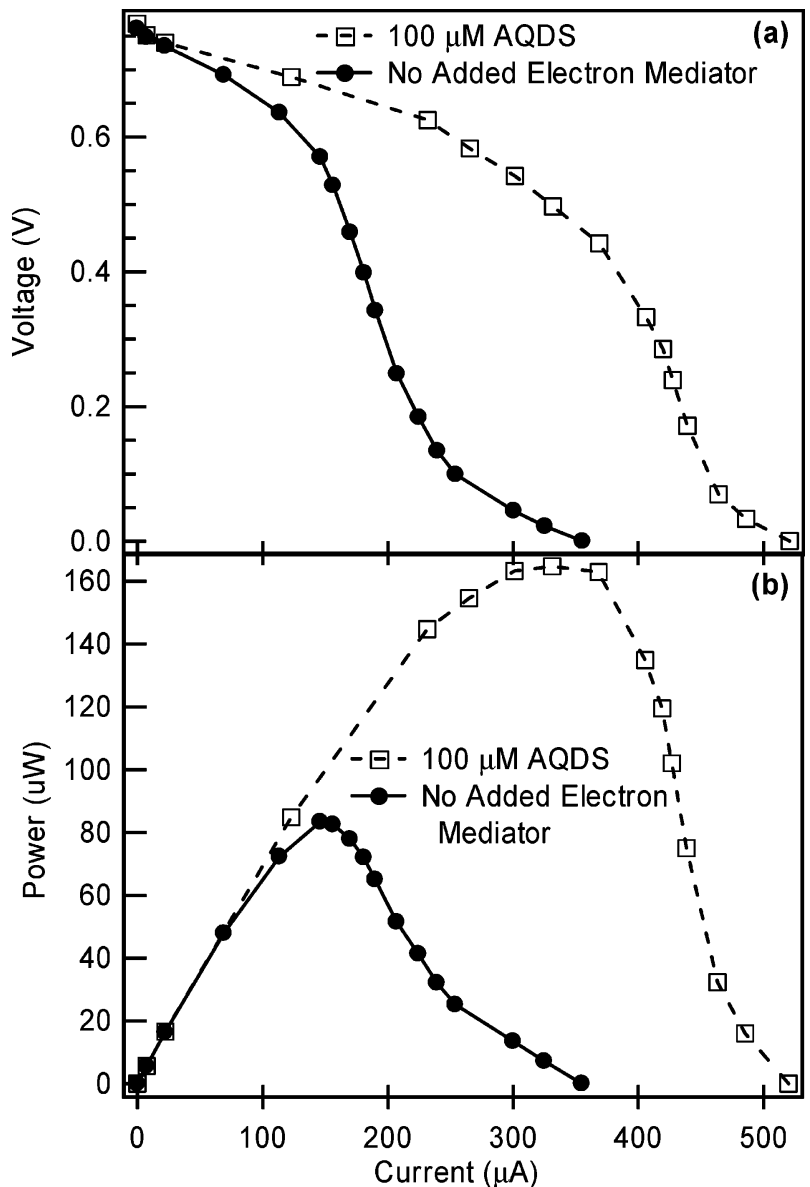

FIGURE 4. (a) Voltage and (b) power versus current for RVC miniMFC running with $(\square)$ and without $(0) 100 \mu \mathrm{M}$ AODS.

the mini-MFC per true surface area. Significantly higher current density and power density per true surface area were found for $\mathrm{RVC}\left(\mathrm{RVC}=44.4 \mathrm{~mA} / \mathrm{m}^{2}, 22.2 \mathrm{~mW} / \mathrm{m}^{2}\right)$ versus GF $\left(20.5 \mathrm{~mA} / \mathrm{m}^{2}, 9.8 \mathrm{~mW} / \mathrm{m}^{2}\right)$. A larger difference was found when short circuit currents were used to calculate the current density per true surface area $\left(\mathrm{RVC}=100 \mathrm{~mA} / \mathrm{m}^{2}\right.$; GF $=32$ $\mathrm{mA} / \mathrm{m}^{2}$ ). As expected, significantly higher current and power densities were calculated when AQDS was present with larger increases observed for RVC $(>100 \%)$ versus GF $(<70 \%)$. The reduced current and power density for GF may indicate that the mini-MFC is operating at its kinetic limit when using 610 $\mathrm{cm}^{2}$ of active surface area in a $1.2 \mathrm{~cm}^{3}$ chamber with a $2 \mathrm{~cm}^{2}$ PEM. Another possibility may be that the reactants cannot efficiently access all of the electrode surface area during their residence time within the cell, reducing the current and power density per true surface area.

Current and power densities for MFCs are often reported per cross-sectional area of the device $\left(2 \mathrm{~cm}^{2}\right)$ or per volume of the anode chamber $\left(1.2 \mathrm{~cm}^{3}\right)(10,25,26)$. The density calculations based on these smaller areas and volumes reversed the previous findings, showing that GF current and power densities far outpaced RVC electrodes. By using the device cross-section, we found current densities (at maximum power) and power densities for the RVC mini-MFC equal to $0.8 \mathrm{~A} / \mathrm{m}^{2}$ and $0.4 \mathrm{~W} / \mathrm{m}^{2}$, while GF electrodes yielded $6.3 \mathrm{~A} / \mathrm{m}^{2}$ and $3.0 \mathrm{~W} / \mathrm{m}^{2}$. Calculations based on the anode chamber volume give current and power densities for the RVC miniMFC of $0.13 \mathrm{kA} / \mathrm{m}^{3}$ and $0.07 \mathrm{~kW} / \mathrm{m}^{3}$, while GF electrodes yield $1.04 \mathrm{kA} / \mathrm{m}^{3}$ and $0.50 \mathrm{~kW} / \mathrm{m}^{3}$. Addition of AQDS to the anolyte increased the densities for GF electrodes, giving values of $11 \mathrm{~A} / \mathrm{m}^{2}, 4.0 \mathrm{~W} / \mathrm{m}^{2}, 1.8 \mathrm{kA} / \mathrm{m}^{3}$ and $0.66 \mathrm{~kW} / \mathrm{m}^{3}$ for cross section and volume calculations, respectively. For scaled up designs based on the mini-MFC, these power densities would

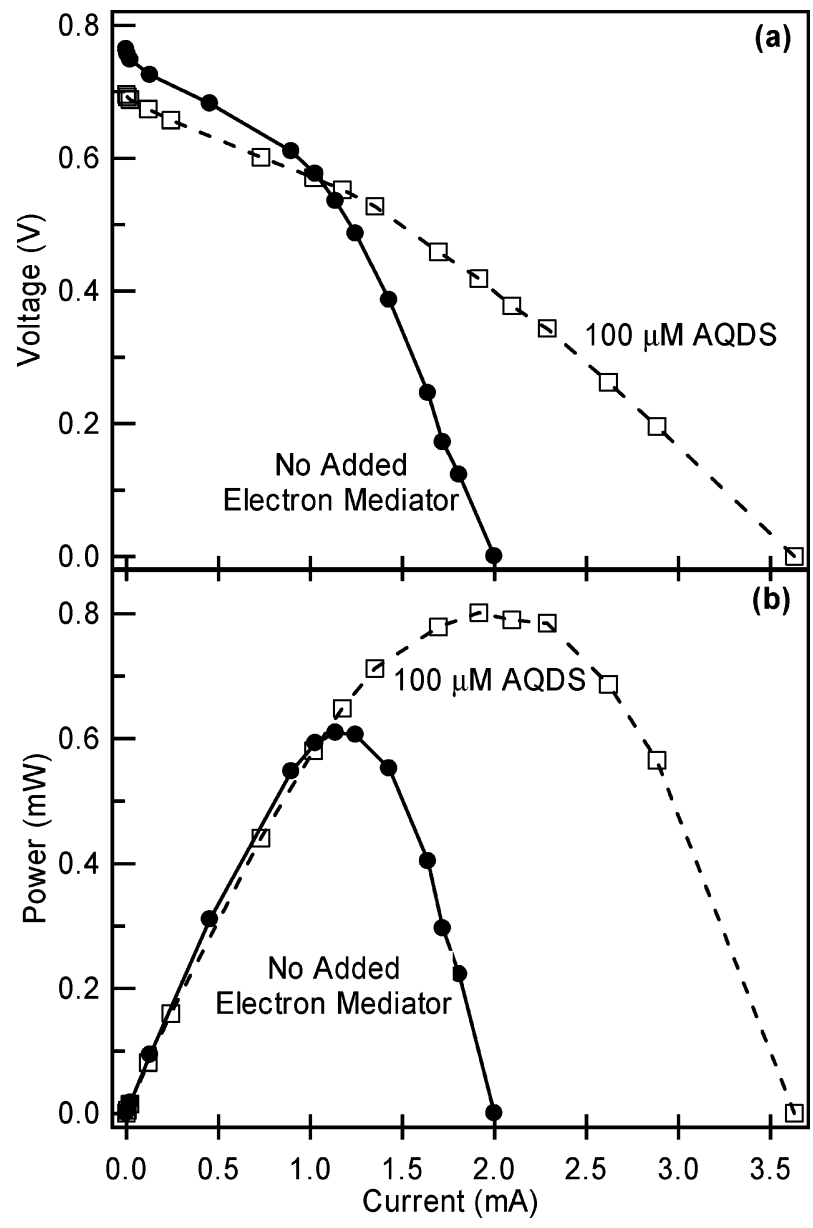

FIGURE 5. (a) Voltage and (b) power versus current for GF miniMFC running with (O) and without ( $\square$ ) $100 \mu$ M AQDS.

most likely be reduced based on increased diffusion lengths. However, an alternative design utilizing several mini-MFCs wired in series or parallel may enable equivalent power density for a larger system.

Mechanism of Electron Transfer. The mechanism for electron transfer in the anode chamber of the mini-MFC is most likely a combination of (a) direct Shewanella-anode electron transfer, (b) indirect Shewanella-mediator (selfexcreted or externally added)-anode transfer, or (c) mediatoranode transfer from mediators previously charged by Shewanella in the reservoir or influent tubing. Based on calculations assuming entirely pre-charged mediators entering the anode chamber ( $100 \mu \mathrm{M}$ AQDS, 1 e- per molecule, $1.5 \mathrm{~mL} / \mathrm{min}$ flow rate), we conclude that the mediator-toanode transfer mechanism would only result in a current of $0.3 \mathrm{~mA}$, which is significantly smaller than the observed maximum current of $3.6 \mathrm{~mA}$ (Figure 5). Additional current may also be generated by pre-charged excreted mediators (Shewanella self-mediated), but the concentration of these mediators would have to be $>1 \mathrm{mM}$ to independently account for the observed output current. Based on the increased current and power we observed upon the addition of AQDS, it seems unreasonable that DSP10 was self-mediating to this extent. Additionally, stopped flow experiments showed a slow decay in current over hundreds of minutes, yielding a charge that could only be generated if lactate was being consumed in the anode chamber by DSP10 (data not shown). We performed these experiments to eliminate the possibility that current was being generated solely by pre-charged mediators entering the anode chamber from the tubing and/or culture reservoir. Taken together, this experiment and the calculation described above imply that a significant portion of the mini- 
MFC current is generated by DSP10 metabolism of lactate in the anode chamber, resulting in direct transfer of electrons to the anode and/or charging/re-charging of mediators in the anode chamber.

Flow Rate Experiments. By measuring general trends in output current with flow rate, mass transfer and kinetic limits in the mini-MFC can be studied. Current at maximum power and short circuit currents were measured at flow rates from 0.6 to $12 \mathrm{~mL} / \mathrm{min}$ with and without exogenous mediators for both RVC and GF electrodes. In all cases, current output remained nearly constant over the entire range of flow rates, with the largest variations ( $<20 \%$ increase) occurring for short circuit currents in the presence of exogenous mediators. These maxima occurred at $3.7 \mathrm{~mA}$ for GF $(\sim 4 \mathrm{~mL} / \mathrm{min})$ and $0.54 \mathrm{~mA}$ for RVC $(7 \mathrm{~mL} / \mathrm{min})$, with minima of 3.4 and 0.45 $\mathrm{mA}$ measured at the lowest flow rate. These results indicate that mass transfer does not play an extensive role in the operation of the mini-MFC.

Comparison with Other MFCs. The MFC presented here is unique in that the system design is smaller than most MFCs in the literature, and that it takes advantage of anode and cathode alignment and reduced spacing to maximize proton transport across the PEM. By aligning the anode and cathode and reducing the distance between them, the device could potentially operate at higher efficiencies than the traditional "H-cell" design still used in many macroscopic MFC experiments. The mini-MFC design is also different from other "flat plate" MFCs in that it allows high surface area, 3D electrodes to be used rather than a pattern of shallow channels in a serpentine path $(10,26)$. Even with a relatively deep chamber $(0.6 \mathrm{~cm})$, the mini-MFC design still maintains a large surface-area-to-volume ratio when graphite felt electrodes are used $\left(510 \mathrm{~cm}^{-1}\right)$, enabling high power densities to be attained. The large surface-area-to-chamber volume ratio also decreases the average distance from any point in the fluid to an electron surface, thus improving the charge transport efficiency for electrons generated inside the anode chamber.

There are two examples of "flat plate" MFCs in the literature, both of which utilize closely spaced, 2D electrodes in a serpentine path. Chiao et al. describes a microfabricated MFC that utilized an anode yeast culture, a ferricyanide catholyte, and a surface area-to-chamber volume ratio of $500 \mathrm{~cm}^{-1}(10)$. Current and power density per true surface area $\left(0.5 \mathrm{~cm}^{2}\right)$ were reported to be $30-100 \mathrm{~mA} / \mathrm{m}^{2}$ and $5 \times$ $10^{-3} \mathrm{~mW} / \mathrm{m}^{2}$ with a power per volume of $0.5 \mathrm{~W} / \mathrm{m}^{3}$. However, very short run times were reported, with a significant drop in output current after only $15 \mathrm{~min}$. We report a similar current density over a period of 7 days and a much higher total current and power output ( $1.3 \mathrm{~mA}$ vs $5.0 \mu \mathrm{A}, 0.60 \mathrm{~mW}$ vs $2.0 \mathrm{nW}$ ) for a similar cross-section device $\left(2 \mathrm{~cm}^{2} \mathrm{vs} 1.5 \mathrm{~cm}^{2}\right)$. In addition, the utilization of high-surface-area $3 \mathrm{D}$ electrodes in the miniMFC increased the power density over 3 orders of magnitude when compared to the $2 \mathrm{D}$ microfabricated device (500 vs 0.5 $\mathrm{W} / \mathrm{m}^{3}$ ). The mini-MFC power per volume is on the same order of magnitude as other energy scavenging sources, making this mini-MFC a potential power source for longfunctioning autonomous sensors (11).

Min and Logan described a "flat plate" MFC that utilizes a serpentine path electrode with a total surface area of 55 $\mathrm{cm}^{2}$ and $22 \mathrm{~cm}^{3}$ chamber volumes for a surface area-tochamber volume ratio of $2.5 \mathrm{~cm}^{-1}$ (26). This ratio is $10-100$ times larger than many traditional MFCs $(1,2,17,19)$, but 200 times smaller than the ratio for our mini-MFC. Domestic wastewater was used in the anode, and the MFC operated with an air cathode (carbon cloth spiked with a Pt catalyst). Relatively high power densities per true surface area were found, ranging from 60 to $300 \mathrm{~mW} / \mathrm{m}^{2}$, depending upon the substrate used. When calculated as a function of crosssectional area, the power density fell to $33-165 \mathrm{~mW} / \mathrm{m}^{2}$, and by using the chamber volume, the power density was calculated to be between 15 and $75 \mathrm{~W} / \mathrm{m}^{3}$. When operating without exogenous mediators, the GF mini-MFC reported here showed increased power density from $9.8 \mathrm{~mW} / \mathrm{m}^{2}$ for true surface area to $3.0 \mathrm{~W} / \mathrm{m}^{2}$ when using the cross-sectional area. This density per cross-sectional area is a factor of 18 times larger than the "flat plate" MFC (for pure substrates, lactate vs acetate). In addition, due to the much higher surface-area-to-chamber volume ratio for the mini-MFC, the power density per chamber volume was over 60 times larger than that of the macroscopic "flat plate" MFC. Part of the reason for this power loss is that the mini-MFC utilized ferricyanide rather than the $\mathrm{Pt} / \mathrm{C}$ air cathode used in the "flat plate" MFC, but this difference should only decrease the power density by less than a factor of $2(22,27)$. This assumption is supported by comparison to a tubular microbial fuel cell that utilized reagent flow, a ferricyanide cathode, and closely spaced electrodes. Even with these similar characteristics, the tubular design produced a power per chamber volume over 30 -fold lower than the mini-MFC (25). In fact, the mini-MFC power density per chamber volume is the highest reported in the literature to date (28).

Traditional serpentine-path 2D channels pose two significant problems for miniature reaction cells. First, fuel is continuously used as it is pumped through the back-andforth channels. This flow cycle results in potentially much lower fuel concentrations at the end of the electrode surface than at the beginning. Second, as the device footprint becomes smaller, the channels also get smaller, increasing the probability for clogging and requiring lower flow rates. The mini-MFC utilizes one entrance and one exit port to create uniform mixing and distribution of fuel and reagents in the chambers. In addition, the ports are utilized over a 1.5 cm diameter chamber, enabling each to be much larger and making them less likely to clog than corresponding serpentine-path channels that have multiple passes over a similar width.

The current and power density reported here for a pure culture represents a significant difference when compared to other macroscopic MFCs. Several recent examples in the MFC literature demonstrate how mixed cultures of microbes significantly enhance power density, with reported values between 3.0 and $4.2 \mathrm{~W} / \mathrm{m}^{2}(29,30)$. When these other MFCs utilized pure cultures, such as the one used in our study, the power decreased by orders of magnitude. One example of a pure culture Shewanella sp. MFC operating without exogenous mediators and utilizing nonchemically altered GF electrodes is reported by Kim et al. (19). Their MFC utilized a pure anaerobic Shewanella putrefaciens culture with a dissolved $\mathrm{O}_{2}$ cathode. With an apparent electrode surface area of $50 \mathrm{~cm}^{2}$, current and power densities were calculated to be $8 \mathrm{~mA} / \mathrm{m}^{2}$ and $0.3 \mathrm{~mW} / \mathrm{m}^{2}$. However, GF electrodes with $50 \mathrm{~cm}^{2}$ of geometric surface area and $3000 \mathrm{~cm}^{2}$ of true surface area were used in this study. Therefore, adjustments based on true surface area yield reduced current and power densities of $130 \mu \mathrm{A} / \mathrm{m}^{2}$ and $5 \mu \mathrm{W} / \mathrm{m}^{2}$. This calculation reveals that the mini-MFC, while using a ferricyanide catholyte and GF electrodes, produced 160 and 1960 times more current and power density than previously reported for a pure culture Shewanella putrefaciens MFC. The use of dissolved oxygen in the cathode chamber could reduce this difference by up to 8-fold (27), but significant differences in performance remain. Based on the comparisons stated above, we believe that the mini-MFC demonstrates that small footprint devices that take advantage of shorter diffusion paths and higher surface area-to-chamber volume ratios could present significant advantages over larger, less efficient designs. 


\section{Acknowledgments}

We thank the Office of Naval Research for funding (NRL 6.2 Program Element Number 62123N) to support this work.

\section{Literature Cited}

(1) Bond, D. R.; Lovely, D. R. Electricity production by Geobacter sulfurreducens attached to electrodes. Appl. Environ. Microbiol. 2003, 69, 1548 .

(2) Liu, H.; Ramnarayanan, R.; Logan, B. E. Production of electricity during wastewater treatment using a single chamber mircrobial fuel cell. Environ. Sci. Technol. 2004, 38, 2281.

(3) Niessen, J.; Schroder, U.; Scholz, F. Exploiting complex carbohydrates for microbial electricity generation-a bacterial fuel cell operating on starch. Electrochem. Commun. 2004, 6, 955.

(4) Chaudhuri, S. K.; Lovley, D. R. Electricity generation by direct oxidation of glucose in mediator less microbial fuel cells. Nat. Biotechnol. 2003, 21, 1229.

(5) Tender, L. M.; Reimers, C. E.; Stecher, H. A.; Holmes, D. E.; Bond, D. R.; Lowy, D. A.; Pilobello, K.; Fertig, S. J.; Lovley, D. R. Harnessing microbially generated power on the seafloor. Nat. Biotechnol. 2002, 20, 821.

(6) Chang, I. S.; Jang, J. K.; Gil, G. C.; Kim, M.; Kim, W. J.; Cho, B. W.; Kim, B. W. Continuous determination of biochemical oxygen demand using microbial fuel cell type biosensor. Biosens. Bioelectron. 2004, 19, 607.

(7) Shantaram, A.; Beyenal, H.; Veluchamy, R. R. A.; Lewandowski, Z. Wireless sensors powered by microbial fuel cells. Environ. Sci. Technol. 2005, 39, 5037.

(8) Chen, T.; Barton, S. C.; Binyamin, G.; Gao, Z.; Zhang, Y.; Kim, H.-H.; Heller, A. A miniature biofuel cell. J. Am. Chem. Soc. 2001, 123, 8630 .

(9) Heller, A. Miniature biofuel cells. Phys. Chem. Chem. Phys. 2004, $6,209$.

(10) Chiao, M.; Lam, K. B.; Lin, L. Micromachined microbial fuel cells. Proceedings of the IEEE Micro Electro Mechanical Systems Conference, Kyoto, Japan; Jan. 2003; p 383.

(11) Roundy, S.; Wright, P. K.; Rabaey, J. A study of low level vibrations as a power source for wirelss sensor nodes. Computer Commun. 2003, 26, 1131.

(12) Roundy, S.; Otis, B. P.; Chee, Y.; Rabaey, J. M.; Wright, P. A. A $1.9 \mathrm{GHz} \mathrm{RF}$ transmit beacon using environmentally scavenged energy; Dig; IEEE Int. Symposium on Low Power Elec. and Devices (ISLPED), Seoul, Korea; 2003.

(13) Mano, N.; Heller, A. A miniature membraneless biofuel cell operating at $0.36 \mathrm{~V}$ under physiological conditions. J. Electrochem. Soc. 2003, 150, A1136.

(14) Kim, H. H.; Mano, N.; Zhang, X. C.; Heller, A. A miniature membrane-less biofuel cell operating under physiological conditions at 0.5 V. J. Electrochem. Soc. 2003, 150, A209.

(15) Schroder, U.; Niessen, J.; Sholz, F. A generation of microbial fuel cells with current outputs boosted by more than one order of magnitude. Angew. Chem. Int. Ed. 2003, 42, 2880.
(16) Shukla, A. K.; Suresh, P.; Berchmans, S.; Rajendran, A. Biological fuel cells and their applications. Curr. Sci. 2004, 87, 455.

(17) Park, D. H.; Zeikus, J. G. Electricity Generation in microbial fuel cells using neutral red as an electronophore. Appl. Environ. Microbiol. 2000, 66, 1292.

(18) Park, D. H.; Zeikus, J. G. Impact of electrode composition on electricity generation in a single-compartment fuel cell using Shewanella putrefaciens. Appl. Microbiol. Biotechnol. 2002, 59, 58.

(19) Kim, H. J.; Park, H. S.; Hyon, M. S.; Chang, I. S.; Kim, M.; Kim, B. H. A mediator-less microbial fuel cell using a metal reducing bacterium, Shewanella putrefaciens. Enzyme Microb. Technol. 2002, 30, 145 .

(20) He, Z.; Minteer, S. D.; Angenent, L. T. Electricity generation from artificial wastewater using an upflow microbial fuel cell. Environ. Sci. Technol. 2005, 39, 5262.

(21) Liu, H.; Logan, B. E. Electricity generation using an air-cathode single chamber microbial fuel cell in the presence and absence of a proton exchange membrane. Environ. Sci. Technol. 2004 38,4040

(22) Oh, S.; Logan, B. E. Proton exchange membrane and electrode surface areas as factors that affect power generation in microbial fuel cells. Appl. Microbiol. Biotechnol. 2005, early view published on-line (September).

(23) Newman, D. K.; Koler, R. A role for excreted quinones in extracellular electron transfer. Nature 2000, 405, 94

(24) Genomes to Life Roadmap, www.doegenomestolife.org/roadmap/ (accessed Jan 16, 2006).

(25) Rabaey, K.; Clauwaert, P.; Aelterman, P.; Verstraete, W. Tubular microbial fuel cells for efficient electricity generation. Environ. Sci. Technol. 2005, 39, 8077.

(26) Min, B.; Logan, B. E. Continuous electricity generation from domestic wastewater and organic substrates in a flat plate microbial fuel cell. Environ. Sci. Technol. 2004, 38, 5809.

(27) Oh, S.; Min, B.; Logan, B. E. Cathode performance as a factor in electricity generation in microbial fuel cells. Environ. Sci. Technol. 2004, 38, 4900 .

(28) Moon, H.; Chang, I. S.; Kim, B. H. Continuous electricity production from artificial wastewater using a mediator-less microbial fuel cell. Bioresour. Technol. 2006, 97, 621.

(29) Rabaey, K.; Lissens, G.; Siciliano, S. D.; Verstraete, W. A microbial fuel cell capable of converting glucose to electricity at high rate and efficiency. Biotechnol. Lett. 2003, 25, 1531.

(30) Rabaey, K.; Boon, N.; Siciliano, S. D.; Verhaege, M.; Verstraete, W. Biofuel cells select for microbial consortia that self-mediate electron transfer. Appl. Environ. Microbiol. 2004, 70, 5373.

Received for review November 9, 2005. Revised manuscript received February 10, 2006. Accepted February 10, 2006.

ES052254W 